\title{
Leiomyosarcoma of the small intestine presenting as fever of unknown origin
}

\author{
P Dendale, G Devis, A Goossens
}

\begin{abstract}
We report a patient with a jejunal leiomyosarcoma who presented with fever of unknown origin. Resection of the tumour resulted in resolution of his symptoms.
\end{abstract}

Jejunal leiomyosarcoma is a rare tumour consisting of smooth muscle cells. Patients with this tumour generally present with vague symptoms such as abdominal pain, chronic anaemia, or diarrhoea and because of this and the low sensitivity of most diagnostic studies - for example, enteroclysis, computed tomography, and echography - jejunal leiomyosarcoma is notoriously difficult to diagnose at an early stage. Histologically, differential diagnosis between leiomyoma and leiomyosarcoma is not clear cut, as it is based on a number of differentiating features with a wide overlap. The tumour typically spreads by direct invasion and haematogenously to the liver, lungs, and bone. The only proved treatment is resection, with a five year survival rate of about $45-60 \%$.

\section{Case report}

A 59 year old man was referred to this hospital because of fever of unknown origin. His symptoms had begun three months earlier with episodes of rigor and a temperature up to $40.5^{\circ} \mathrm{C}$, followed by general fatigue. In addition he complained of anorexia and weight loss of $4 \mathrm{~kg}$ in the previous six months.

The patient was a furniture salesman and had smoked a pack of cigarettes a day for 20 years. $\mathrm{He}$ drank moderate amounts of alcohol and coffee. Clinical examination showed a man in good general condition with a normal rectal temperature, no thyroid enlargement, no lymphadenopathy, and a normal thorax and abdominal examination.

Blood cultures during bouts of fever were repeatedly negative. Blood analysis was normal, except for a low iron concentration (with normal iron binding capacity) and an erythrocyte sedimentation rate of $25 \mathrm{~mm}$ after one hour. Thyroid tests and tumour markers were normal. Stool examination showed a trace of blood on one occasion.

Gastroscopy, colonoscopy, and barium enema examinations were normal, as were a small intestine contrast study and an upper abdominal ultrasound scan. Sinus and thorax $x$ ray, prostate echography, and spinal fluid examination were negative.

A further blood analysis three weeks later showed a severe microcytic anaemia, while the patient admitted some episodes of melaena, but no haematemesis or haematuria.
A computed tomogram of the abdomen showed a large $(8 \times 5.5 \mathrm{~cm})$ mass in the right iliac fossa that seemed to be in contact with the small intestine. There was no sign of retroperitoneal lymph node enlargement, and the mass showed central necrosis.

A laparotomy was performed, with resection of a necrotic small intestinal tumour at a distance of $100 \mathrm{~cm}$ from the iliocaecal valve, on the antimesenteric aspect. The tumour was adherent to the urinary bladder and the sigmoid. There were no signs of liver or peritoneal cavity metastases. Postoperative progress was normal and the patient showed no recurrence of the fever or tumour in the 12 months follow up.

The macroscopic examination showed a nodular, fleshy white-gray mass with a diameter of $6.5 \mathrm{~cm}$ and a central cyst formation that contained brown sterile fluid. Microscopic tumour examination showed well differentiated smooth muscle cells with slightly pleomorphic, hyperchromatic nuclei and abundant eosinophilic cytoplasm (Fig 1). The number of mitoses was 3 to 5 per 10 high power field (Fig 2). There was invasion of the mucosa as well as the serosa with local perforation and signs of localised peritonitis. The edges of the resected small bowel fragment consisted of normal intestinal tissue. The resected lymph nodes were normal.

\section{Discussion}

A leiomyosarcoma of the jejunum presenting with bouts of spiking fever has not been described recently in the published reports. The tumour usually presents with melaena, ${ }^{1-3}$ because of ulceration, or with abdominal cramps, signs of subacute obstruction, or volvulus. ${ }^{4}$ Chronic diarrhoea ${ }^{5}$ or, rarely, spontaneous perforations ${ }^{6}$ also occur. In our patient central necrosis with localised peritonitis as a consequence of a small perforation probably caused the presenting symptom - fever. In the course of the diagnostic investigations, the patient showed signs of melaena and microcytic anaemia.

We found, in published reports, references to leiomyosarcomas or leiomyomas of other organs presenting with fever - surgical removal of an uterine myoma, ${ }^{7}$ a leiomyosarcoma of the lung with fever, cough, and dyspnoea ${ }^{8}$; a renal leiomyosarcoma with signs of pyelonephritis'; and a leiomyosarcoma of the spleen presenting with fever. ${ }^{10}$ In the gastrointestinal tract there were reports of a large bowel leiomyosarcoma," a stomach leiomyosarcoma ${ }^{12}$ that caused fever and anaemia, and an oesophageal leiomyosarcoma $^{13}$ that presented with fever, cough, pyrosis, and dysphagia.

The diagnosis of small intestinal leiomyo- 


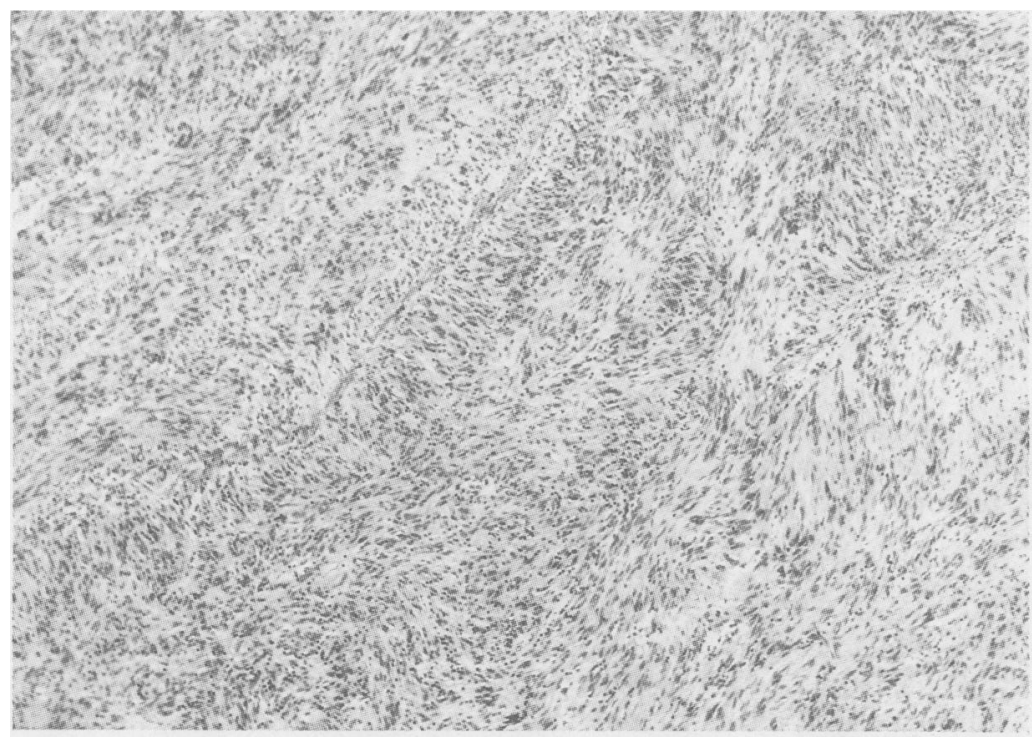

Figure 1: Well differentiated leiomyosarcoma with a rather orderly fascicular pattern but presence of hyperchromatic nuclei (haematoxylin and eosin, original magnification $\times 120$ ).

sarcoma is a difficult one, so only rarely in this kind of tumour diagnosed in an early stage.

The most sensitive examination is reported to be a small bowel enteroclysis, ${ }^{14}$ which commonly shows an extraluminal mass with a crater like defect. The extraluminal growth is a possible explanation for the absence of any sign on our small intestinal $x$ ray examination. Even with hindsight, we could not find any mucosal defect or sign of extrinsic compression on $x$ rays, notwithstanding the description of a small mucosal ulceration in the histological report. An abdominal computed tomogram is useful for detecting large tumour masses, as in our case, but it may also miss smaller lesions. An abdominal ultrasound examination may also show large lesions, if specifically sought, but echographic examination of the small intestine is often negative because of artefacts caused by air in the intestine.

Selective visceral angiography ${ }^{615}$ has been

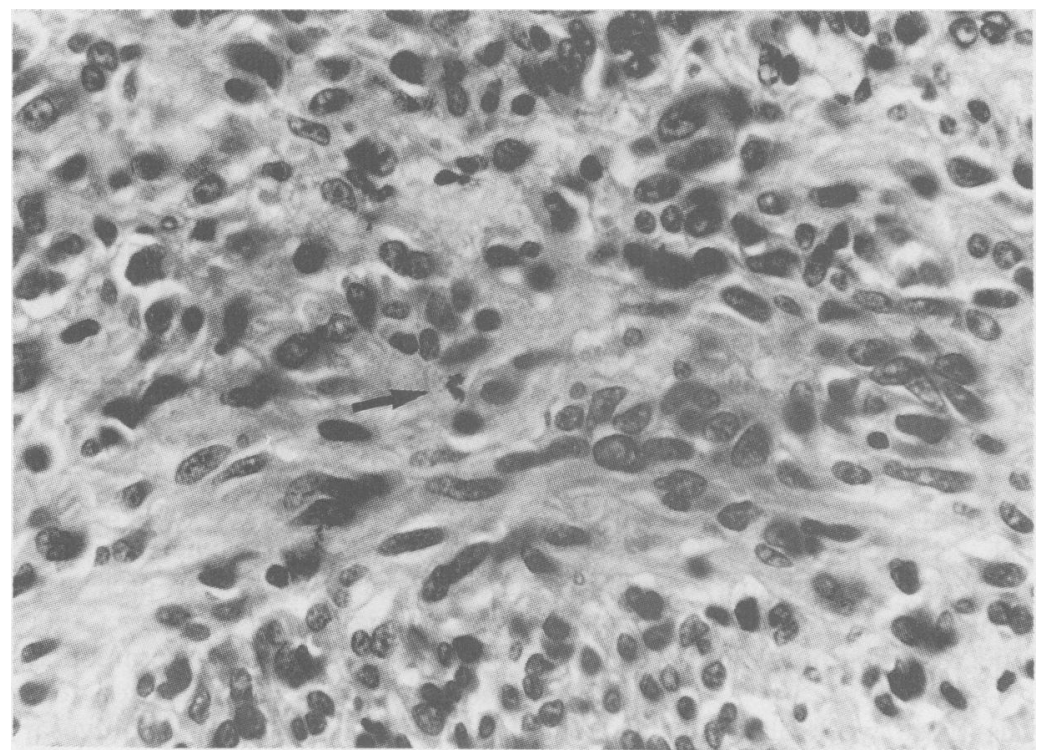

Figure 2: Cytological features of the tumour showing slightly pleiomorphic and hyperchromatic nuclei and an atypical mitosis (arrow) in the centre of the field (haematoxylin and eosin, original magnification $\times 650$ ). described as a very sensitive way of detecting leiomyosarcomas of the small bowel: the neoplasms are highly vascular which facilitates recognition. Scintigraphy with Technetium labelled red blood cells ${ }^{16}$ is used to detect lesions in which active (even small) haemorrhage occurs. One report describes its use in lesions that were not bleeding actively: the tumour showed hypervascularity. In our case we did not perform these studies as the presenting symptom was fever and not blood loss.

The only proved treatment for leiomyosarcomas of the jejunum is wide excision of the tumour with all areas of invasion. There are no conclusive reports that adjuvant radiotherapy or chemotherapy is helpful.

The five year survival after en bloc resection shows only slight variation between most series: $50 \%,{ }^{17} 48 \cdot 5 \%,{ }^{18} 20$ to $50 \%,{ }^{19}$ and $57 \% .{ }^{20}$

The spread of small intestinal leiomyosarcomas is primarily by direct invasion, as well as by the haematogenous route. Most metastases occur in lungs, liver, and bone. Only a few cases of lymphatic spread have been reported. In our case, the routinely resected lymph nodes did not show any sign of tumour, nor did we find any indication of metastases. The cutting edges were free.

The anatomopathological differential diagnosis between leiomyoma and leiomyosarcoma is not clear cut: it is based on several criteria which all show some overlap. A large histological review ${ }^{21}$ studied the indicators of malignancy based on postoperative behaviour, and found the number of mitoses to be the most useful discriminating feature: all tumours with $\geqslant 5$ mitoses/10 HPF behaved aggressively and should be diagnosed as leiomyosarcoma. On the other hand, however, $40 \%$ of these tumours had fewer than 5 units/10 HPF. In our patient the number of mitoses/10 HPF was 3-5 (Fig 2). As the review series was based on the highest number of mitoses in 5-10 HPFs examined we could consider our case as borderline on this criterion alone. Tumour necrosis was reported to be closely related to invasive potential. So even a tumour with $<5$ mitoses/10 HPF should be considered potentially malignant in cases with extensive necrosis: 31 out of 33 cases of tumour necrosis in this series were leiomyosarcomas.

Further minor parameters studied were tumour size, cellularity, and cellular atypia. In general leiomyosarcomas were larger than leiomyomas and all small intestinal tumours larger than $4 \mathrm{~cm}$ were malignant in this study. Appreciable cellular atypia was not common in the review, and when present, was always associated with malignancy. Prominent cellularity was more frequent in sarcomas, but there was a considerable overlap.

In our patient, the tumour size of $6.5 \mathrm{~cm}$, as well as the noticeable cellularity and necrosis, were arguments for malignancy, whereas the high degree of differentiation, with only minor cellular atypias, points in the opposite direction.

From weighing the different major and minor anatomophysiological criteria, we decided we had to consider this tumour as malignant. The longterm follow up of this patient should give the answer to this difficult question. 
1 Gadaleanu V, Popescu V. Angiomyoma and vascular ectasia of the small bowel as a cause of intestinal bleeding. Pathol Res Pract 1988; 183: 519-23.

2 Walters NA, Thomson KR. Leiomyoma causing massive gastrointestinal blood loss. A case report. Australas Radiol gastrointestinal bl $32: 138-40$.

3 Friend PJ, Adair HM, Greatorex RA. Gastro-intestinal bleeding from small bowel leiomyomata. $\mathcal{F} R$ Coll Surg Edinb 1987; 32: 173-5.

4 Hershman $M J$. Small bowel volvulus due to a leiomyoma of the mesentery. $\mathcal{F} R$ Coll Surg Edinb 1987; 32: 378-9.

5 Maglinte DD, $\mathrm{Ng} \mathrm{AC}$, Isenberg MT. Leiomyoma in a 'blind pouch.' Dig Dis Sci 1984; 29: 376-9.

6 Laursen E, Lyng KM. Leiomyomas of the small intestine: a rare cause of abdominal emergency. Case report. Acta Chir Scand 1987; 153: 391-3.

7 Prichard JG, Lowenstein MH, Silverman IJ, Brennan AC. Streptococcus milleri pyomyoma simulating infective endocarditis. Obstet Gynecol 1986; 68 (suppl 3): 468-95.

8 Beluffi G, Bertolotti P, Mietta A, Manara G, Luisetti M. Primary leiomyosarcoma of the lung in a girl. Pediatr Radiol 1986; 16: $240-4$.

9 Kobayashi M, Sai S, Kato T, Aota Y, Sahashi M. A case of leiomyosarcoma of the kidney. Hinyokika Kiyo 1987; 33: leiomyosarcoma of the kidney. Hinyokika Kiyo 1987; 33:
1218-20. 10 Jime-20.

0 Jimenez E, Viciana P, Gomez E, Creagh R, Palomino J, Cuello JA. Leiomiosarcoma de hilio esplenico: causa de sindrome febril. Med Clin 1984; 83: 473-4.

11 Witt JH, Marks MI, Smith EI, Aitshule G, Wilson DA,
Humphrey GB. Leiomyoma presenting as prolonged fever, anemia, and thrombocytosis. Cancer 1983; 52: 2359-62.

12 de la Figuera M, Garriga B, Marquet R, del Mar Vilar M, Villardele $M$. Sindrome febril prolongado y leiomiosarcoma gastrico. Med Clin 1983;81: 924 .

13 Gallinger S, Steinhardt MI, Goldberg M. Giant leiomyoma of the esophagus. Am 7 Gastroenterol 1983; 78: 708-11.

14 Maglinte DD, Hall R, Miller RE, et al. Detection of surgical lesions of the small bowel by enteroclysis. Am $\mathcal{F}$ Surg 1984; 147: $225-9$.

15 Burrows FGO, Dodds WW, Thompson H. Diagnosis of a leiomyoma of the small intestine by selective angiography. Br F Surg 1977; 64: 145-6.

16 McDonald KL. Technetium-99m RBC scintigraphy in the evaluation of small bowel leiomyoma. Clin Nucl Med 1987; 12: 131-3.

17 Griffioen G, Jeurissen ME. Maligne tumoren uitgaande van de dunne darm. Ned Tÿdschr Geneeskd 1986; 130: 528-31.

18 Ashley SW, Wells SA Jr. Tumors of the small intestine. Semin Oncol 1988; 15: 116-28.

19 Bahnini A, Hakami F, Halleb A, et al. Les leiomyosarcomes de l'intestin grêle. A propos de 3 cas. $\mathcal{F}$ Chir 1985; 122: 215-20. 20 Matsushita $M$, Hachisuka $K$, Yamaguchi $A$, et al. Results of Nippon Geka Gakkai Zasshi 1987; 88: 832-8.

21 Ranchod H, Kempson RL. Smooth muscle tumors of the gastrointestinal tract and retroperitoneum. Cancer 1977; 39: 255-62. 